\title{
Amostragem probabilística no controle da qualidade da água para o consumo humano
}

\section{Probabilistic sampling in the control of quality for human consumption}

\author{
Waldir Medri ${ }^{1}$; José da Costa Soeiro ${ }^{2}$; Ana Satie Yotsumoto 3 ; José Carlos Dalmas ${ }^{4}$; \\ Marcelo Medre Nóbrega ${ }^{5}$
}

\section{Resumo}

\begin{abstract}
Alguns fatores podem interferir nas características da água, na rede de distribuição, tanto ao longo dos setores que compõem a rede como ao longo do tempo, o que acaba por comprometer a sua qualidade. Isto pode se dar mesmo que a água tenha saído dos sistemas produtores-distribuidores conforme os parâmetros qualitativos exigidos como aceitáveis. Para garantir a qualidade da água produzida são realizadas coletas de amostras de água ao longo da rede de distribuição e são priorizados os locais de maior concentração, bem como, os de maior probabilidade de contaminação. O objetivo deste estudo é apresentar um plano mensal de amostragem de coleta da água, fundamentado em critérios estatísticos e em pontos estratégicos que sejam representativos do sistema de abastecimento da água a ser avaliado, por meio do monitoramento dos resultados da inspeção, com base nas cartas de controle e em conformidade com a Portaria 518, de 25 de março de 2004, do Ministério da Saúde. Dos parâmetros analisados: Cloro, Flúor, Turbidez, pH e Cor, apenas a turbidez e a cor não estão sob controle estatístico, porém, estão em conformidade com a Portaria 518 MS. Os resultados demonstram que houve uma oscilação na concentração dos parâmetros analisados durante o período de avaliação. As médias foram: cloro $0,86 \mathrm{mg} / 1$, flúor $0,79 \mathrm{mg} / 1$, turbidez $0,49 \mathrm{uT}$, pH 6,72 e cor 1,49 uH.
\end{abstract}

Palavras-chave: Redes de distribuição. Controle estatístico. Qualidade da água.

\begin{abstract}
Several factors can interfere with water features, the distribution network, both across sectors that make up the network and over time, which in turn compromises its quality. This can happen even if the water has come from producers-distributors systems in accordance with the quality parameters required as acceptable. To ensure the quality of the produced water, water samples are collected along the distribution network and the higher concentration sites are prioritized, as well as those with greater probability of contamination. The purpose of this study is to present a monthly plan for water collection sampling, based on statistical criteria and strategic points which are representative of the water supply system to be evaluated by monitoring the results of the inspection, based on control charts and in
\end{abstract}

\footnotetext{
1 Professores Doutores do Departamento de Estatística - CCE/UEL.

2 Professores Mestres do Departamento de Estatística - CCE/UEL.

3 Professores Mestres do Departamento de Estatística - CCE/UEL.

${ }^{4}$ Professores Doutores do Departamento de Estatística - CCE/UEL.

5 Discente da Universidade de São Paulo - USP.
} 
accordance with Ordinance 518 of March 25, 2004, of the Ministry of Health. From the analyzed parameters: Chlorine, Fluoride, Turbidity, $\mathrm{pH}$ and color, only the turbidity and color are not under statistical control, however, they are in accordance with Ordinance 518 MS. The results show that there was a fluctuation in the concentration of the parameters analyzed during the evaluation period. The averages were: chlorine $0.86 \mathrm{mg} / 1$, fluoride $0.79 \mathrm{mg} /$, turbidity $0.49 \mathrm{uT}, \mathrm{pH} 6.72$ and color $1.49 \mathrm{uH}$.

Keywords: Distribution networks. Statistical control. Water quality.

\section{Introdução}

A água caracteriza-se como um ambiente de vida dos mais importantes, uma vez que a maior parte dos seres vivos é aquática, e como elemento vital para a natureza e para o homem. Além de ser fundamental nos processos biológicos, a água é utilizada, pelo homem, como matéria prima, alimento, e na irrigação, assim como, para navegação, para geração de energia elétrica, para a refrigeração de máquinas, para a limpeza e transporte de resíduos em geral e em processos industriais.

As Empresas responsáveis pelo tratamento público da água têm a responsabilidade de manter um controle preventivo, sob vigilância permanente, da potabilidade desta, desde a sua saída da Estação de Tratamento de Água (ETA) até a sua entrada nas ligações domiciliares, uma vez que a água destinada ao consumo humano pode constituir um risco potencial para a saúde, quando nela estiverem presentes agentes nocivos.

Há vários fatores que podem degradar a qualidade da água, tais como: a intermitência no sistema de abastecimento, que gera pressões negativas na rede; as variações de velocidade de escoamento; os vazamentos; e os rompimentos.

Os problemas da qualidade da água, em sistemas de distribuição, são fortemente influenciados por diversos fatores, que incluem: o decaimento do cloro residual; o aumento de bactérias devido à temperatura; e a presença do carbono orgânico assimilável (LECHEVALLIER, 1990).

Para garantir a qualidade da água produzida e distribuída, há necessidade de se realizar coletas de amostras de água ao longo de toda a rede de distribuição, priorizando os locais de maior concentração, entre os quais, destacam-se hospitais, shoppings, escolas, asilos, creches, postos de saúde etc.; bem como, os de maior probabilidade de contaminação, como pontos de baixo cloro residual, de alta turbidez, de ponta de rede, de má circulação de água, entre outros (MEDRI; COSTA, 2001).

Dessa forma, foi desenvolvido um plano mensal de amostragem que buscou atender as exigências da Portaria No 518, de 25 de março de 2004, do Ministério da Saúde. Essa Portaria estabelece os VMPs - Valores Máximos Permissíveis, ou seja, os parâmetros para a qualidade da água tratada, na saída do sistema distribuidor até o cavalete (hidrômetro), ponto de entrega do produtor ao consumidor. Essa Portaria indica o número mínimo de amostras mensais a serem coletadas e a frequência mínima de amostragem para o controle da qualidade da água do sistema de abastecimento, para fins de análises físicas, químicas e microbiológicas, em função da população abastecida. Porém, cabe ressaltar que essa Portaria não dá orientações sobre a localização dos pontos de amostragem.

Essa análise da água compreende a verificação da presença ou ausência de contaminação por meio de bactérias do grupo coliformes. As bactérias coliformes constituem um grupo de organismos com características comuns, cuja presença guarda relação com bactérias patogênicas e vírus e, desse modo, são convenientemente, utilizadas como indicadores de contaminação. Isto quer dizer que, na análise bacteriológica em que estiverem ausentes os coliformes, não há contaminação. Por outro lado, quando a análise acusar a presença de coliformes, isto não quer dizer, necessariamente, 
que a água esteja contaminada, mas a probabilidade de ocorrência é grande.

Desse modo, neste trabalho, foi desenvolvido um modelo mensal de amostragem randômica para a coleta da água, na rede de distribuição, com o objetivo de estabelecer o controle preventivo desta, desde a sua entrada no sistema de distribuição até as ligações domiciliares, de modo atender a potabilidade exigidas pela Portaria 518/04.

Caso os resultados obtidos na amostragem não se apresente em conformidade com os padrões, serão efetuadas medidas corretivas e novas coletas de amostras para a verificação da potabilidade da água. Os pontos de coleta bem como o setor correspondente terão sua frequência intensificada.

\section{Materiais e Métodos}

O modelo de amostragem desenvolvido nesse estudo é uma técnica da qual o sanitarista poderá lançar mão para efetuar um controle, com rigor matemático, do sistema distribuidor, desde que os pontos escolhidos para a coleta sejam representativos. Esses pontos, que foram estabelecidos segundo a experiência do setor de coleta de amostras para análises bacteriológicas, estão diretamente relacionados aos locais onde existe maior probabilidade de contaminação e onde há maior responsabilidade social, além de outros locais, para que se possa ter uma cobertura total da rede de distribuição (COSTA; MEDRI; SANTOS, 2002; MEDRI; COSTA, 2001; MEDRI, 1993).

O Sistema de Abastecimento Público, escolhido para a realização deste trabalho, foi o Serviço Autônomo Municipal de Água e Esgoto de Ibiporã$\operatorname{Pr}$ (SAMAE). A rede de distribuição de água foi dividida em 17 setores de amostragem. Os setores foram constituídos de pontos representativos de coleta, que variaram de dois até cinco e foram classificados em: ponto de maior probabilidade de contaminação, ao qual se atribuiu pesos de 0,1 e 0,2 ; pontos em locais onde há maior responsabilidade social, isto é, de maior concentração de pessoas, aos quais se atribuiu pesos de 0,1 e 0,2 ; e os outros locais de coleta, aos quais atribuiu-se o peso de 0,1 . A delimitação dos setores de amostragem foi feita segundo um critério empírico, e compreendeu cerca de dez quarteirões (quando possível), podendo um setor ser um conjunto habitacional, uma vila, um bairro etc. (MEDRI; COSTA, 2001).

Uma vez estabelecidas as conceituações e as classificações fundamentais do modelo de amostragem, tornou-se necessário construir um modelo operacional. As amostras da água foram colhidas, semanalmente, entre os meses de janeiro e dezembro de 2009, na rede de distribuição, nos pontos cadastrados, para os seguintes parâmetros: bacteriologia, cloro residual livre, flúor, turbidez, pH e cor, de acordo com os métodos estabelecidos pelo "Standart Methods" (AMERICAN PUBLIC HEALTH ASSOCIATION, 1998). No dia da coleta, geralmente às segundas feiras, a mesma foi realizada em 14 pontos, perfazendo um total de 56 coletas, no mês de 4 semanas, e 70, no mês de 5 semanas, contabilizando um total de 728 coletas e análises para cada parâmetro. As coletas foram efetuadas de modo que, em cada mês, se obtivesse uma amostragem relativa a toda a rede de distribuição.

É importante ressaltar que, neste estudo, a definição dos pontos de coleta fundamentou-se em critérios empíricos, o que possibilita a adaptação dos conceitos aqui propostos a novas situações. Por outro lado, a localização desses pontos é dinâmica, podendo ser mudada a qualquer momento. Por exemplo, um ponto que hoje é final de rede, pode, amanhã, não ser, ou um ponto onde, hoje, não há rede de esgoto, amanhã pode ter.

O programa computacional, em pascal, desenvolvido para esse modelo, gera, randomicamente, os pontos de coleta do mês associados aos respectivos setores de amostragem cadastrados.

Neste modelo, a cada coleta em um ponto, subtraí-se o valor de 0,1 do respectivo valor do 
ponto e, também, do setor de amostragem. Se, num mesmo setor de amostragem, forem coletados em dois pontos, subtrai-se 0,1 de cada ponto e 0,2 do respectivo setor de amostragem.

A metodologia utilizou as Cartas de Controle por variáveis quantitativas, para os parâmetros: cloro residual, flúor, turbidez, $\mathrm{pH}$ e cor, na rede de distribuição, que têm por objetivo medir a grandeza das variações, com a finalidade de garantir os padrões de potabilidade da água, de acordo com a Portaria no 518/2004.

É importante salientar que a avaliação da qualidade da água para o abastecimento público deve ser monitorada de forma contínua e intensa, para que possa atender a todos os requisitos mínimos exigidos pela lei. Para tal, as autoridades sanitárias e ambientais devem investir em programas multicriteriosos que atendam à realidade local (ABREU et al., 2000).

O cloro residual livre $(\mathrm{mg} / \mathrm{l})$ é a quantidade de cloro que permanece na água depois do processo de desinfecção da mesma, sendo, desta forma, uma garantia da desinfecção ao longo das redes de distribuição. A turbidez (uT) é o nível de resistência da água à passagem de luz devido à presença de partículas em suspensão, o que reduz a transparência da mesma e pode deixá-la com aspecto turvo. A cor (uH) que também é medida, que indica a presença de substâncias dissolvidas na água, ou finamente divididas. O Flúor (mg/l) é um elemento químico adicionado à água de abastecimento, durante o tratamento, devido à sua comprovada eficácia na proteção dos dentes contra a cárie. $\mathrm{O}$ pH é medido para se estabelecer a condição ácida ou básica (alcalina) da água.

\section{Cartas de controle}

O tratamento estatístico foi realizado por meio das cartas de controle, cujo objetivo é avisar se existem anomalias em algum local na rede de distribuição de água, o que pode dar origem à água contaminada ou a algum parâmetro fora da especificação. Assim, as cartas de controle permitem saber, em determinado instante, se um local está ou não sob controle estatístico. Tais cartas de controle baseiam-se na inspeção adequada de cada caso e podem ser classificadas por atributos e por variáveis. As cartas de controle por atributos são baseadas na distribuição Binomial, enquanto cartas por variáveis são baseadas na distribuição Normal.

Este estudo usou apenas as cartas de controle por variáveis, que realizam mensurações das características do nível de qualidade de atendimento da água, no processo de distribuição, em algum local representativo da rede que sofre variações contínuas.

As cartas de controle por variáveis são realizadas por meio dos pares: média $(\bar{x})$ e desvio padrão (s). $\mathrm{Na}$ prática, os parâmetros média e desvio padrão populacional são desconhecidos. Neste caso, faz-se necessário calcular suas estimativas.

Pelo estudo da teoria da amostragem, fica claro que a melhor estimativa de média populacional $(\mu)$ é a média amostral $(\bar{x})$, e do desvio padrão populacional $(\sigma)$, é o desvio padrão amostral (s). Cabe ressaltar que a média das médias das amostras é dada por:

$$
\overline{\bar{x}}=\frac{1}{k}\left(\bar{x}_{1}+\bar{x}_{2}+\cdots+\bar{x}_{k}\right) \text {, onde é a média da }
$$
primeira amostra, , a da segunda amostra, e assim por diante.

Já o desvio padrão médio é calculado da seguinte maneira:

$\bar{s}=\frac{1}{k}\left(s_{1}+s_{2}+\cdots+s_{k}\right)$, onde s1 é o desvio padrão da primeira amostra, s2, o da segunda amostra, e assim por diante.

A linha média e os limites de controle são, portanto, conforme Montgomery (2004): 


$$
\begin{aligned}
& M=\overline{\bar{x}} \\
& L S C=\overline{\bar{x}}+A_{1} \bar{s} \\
& L I C=\overline{\bar{x}}-A_{1} \cdot \bar{s}
\end{aligned}
$$

onde: LM é a Linha Média; LSC é o Limite Superior de Controle; e LIC é o Limite Inferior de Controle. Os valores de (A1), em função do tamanho (n) da amostra, estão tabelados.

\section{Resultados}

As cartas de controle se mostraram úteis para os responsáveis pelo controle de qualidade da água distribuída à população, especialmente, quando há um grande número de amostras e se deseja levantar se as mudanças apresentadas pelos resultados decorrem de variações estatísticas inerentes ao processo e se estas são significativas.

Este estudo desenvolveu um controle da qualidade da água, na rede de distribuição, com o objetivo de verificar se o processo, nos diversos setores, está sob controle estatístico, conforme os parâmetros estabelecidos. Assim na Tabela 1, são apresentados os valores médios dos parâmetros, $\mathrm{pH}$, cor, cloro residual, flúor e turbidez, dos setores de amostragem, para cada mês, no período de janeiro a junho de 2009.

Tabela 1 - Resultados para: cloro residual, flúor, turbidez, $\mathrm{pH}$ e cor, dos setores de amostragem, no período de janeiro a dezembro de 2009.

\begin{tabular}{llllll}
\hline Setor & $\begin{array}{c}\text { Cloro } \\
(\mathrm{mg} / \mathrm{l})\end{array}$ & $\begin{array}{c}\text { Flúor T } \\
(\mathrm{mg} / \mathrm{l})\end{array}$ & $\begin{array}{c}\text { urbidez } \\
(\mathrm{uT})\end{array}$ & $\mathrm{pH}$ & $\begin{array}{c}\text { Cor } \\
(\mathrm{uH})\end{array}$ \\
\hline $\mathrm{N}^{1}$ & 0,89 & 0,79 & 0,50 & 6,75 & 1,78 \\
$\mathrm{~N}^{2}$ & 0,90 & 0,81 & 0,37 & 6,74 & 1,26 \\
$\mathrm{~N}^{3}$ & 0,85 & 0,76 & 0,62 & 6,75 & 1,72 \\
$\mathrm{~N}^{4}$ & 0,89 & 0,79 & 0,75 & 6,74 & 1,50 \\
$\mathrm{~N}^{5}$ & 0,88 & 0,78 & 0,58 & 6,72 & 1,65 \\
$\mathrm{~N}^{6}$ & 0,86 & 0,81 & 0,60 & 6,71 & 1,65 \\
$\mathrm{~N}^{7}$ & 0,85 & 0,79 & 0,54 & 6,78 & 2,66 \\
$\mathrm{~N}^{8}$ & 0,90 & 0,81 & 0,46 & 6,65 & 1,62 \\
$\mathrm{~N}^{9}$ & 0,86 & 0,78 & 0,61 & 6,66 & 1,29 \\
$\mathrm{~N}^{10}$ & 0,87 & 0,79 & 0,57 & 6,74 & 1,22 \\
$\mathrm{~N}^{11}$ & 0,84 & 0,81 & 0,59 & 6,75 & 1,63 \\
$\mathrm{~N}^{12}$ & 0,86 & 0,79 & 0,47 & 6,73 & 1,83 \\
$\mathrm{~N}^{13}$ & 0,82 & 0,78 & 0,55 & 6,73 & 1,36 \\
$\mathrm{~N}^{14}$ & 0,84 & 0,82 & 0,41 & 6,74 & 1,23 \\
$\mathrm{~N}^{15}$ & 0,83 & 0,78 & 0,26 & 6,71 & 1,02 \\
$\mathrm{~N}^{16}$ & 0,82 & 0,76 & 0,28 & 6,70 & 0,90 \\
$\mathrm{~N}^{17}$ & 0,84 & 0,77 & 0,18 & 6,67 & 0,81 \\
\hline
\end{tabular}

Fonte: Os autores 
As cartas de controle dos pares média/desviopadrão dos parâmetros analisados, no período de janeiro a dezembro de 2009, são apresentados a seguir

Os limites de controle superior e inferior bem como a linha média são dados por:

$$
\begin{aligned}
& M=\stackrel{\bar{x}}{L} \quad L M=\overline{\bar{x}}=0,86 \\
& L S C=\overline{\bar{x}}+A_{1} \cdot \bar{s} \rightarrow L S C=\overline{\bar{x}}+A_{1} \cdot \bar{s}=0,86+0,925 x 0, \overline{0} 7=0,92 \\
& L I C=\overline{\bar{x}}-A_{1} \overline{\cdot s} \quad L I C=\overline{\bar{x}}-A_{1} \cdot \bar{s}=0,86-0,9251 x 0,07=0,92
\end{aligned}
$$

A carta de controle dos pares média/desviopadrão do cloro residual, dos setores de amostragem, no período de janeiro a dezembro de 2009, é apresentada na Figura 1.

Figura 1 - Cloro residual (mg/l) nos setores de amostragem da rede de distribuição.

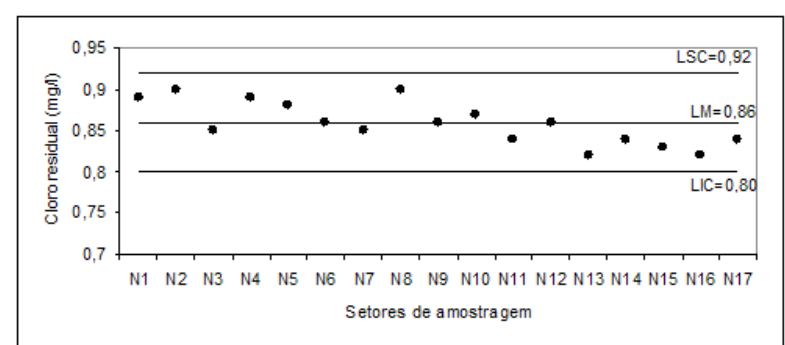

Fonte: Adaptado pelos autores

Nota-se pela carta de controle (Figura 1), que o processo está sob Controle Estatístico de Qualidade, ou seja, a rede de distribuição de água apresenta uma água adequada para o consumidor, já que nenhum ponto caiu fora da região de normalidade.

A Portaria No 518, de 25 de março de 2004, do Ministério da Saúde, recomenda que o teor máximo de cloro residual livre, em qualquer ponto do sistema de abastecimento, seja de 2,0 mg/l, e o teor mínimo, de $0,5 \mathrm{mg} / \mathrm{l}$, e exige a manutenção de, no mínimo, $0,2 \mathrm{mg} / 1$, em qualquer ponto da rede de distribuição.

A carta de controle do Flúor, nos setores de amostragem, no período de janeiro a dezembro de 2009, está apresentada na Figura 2.
Figura 2 - Flúor (mg/l) nos setores de amostragem da rede de distribuição.

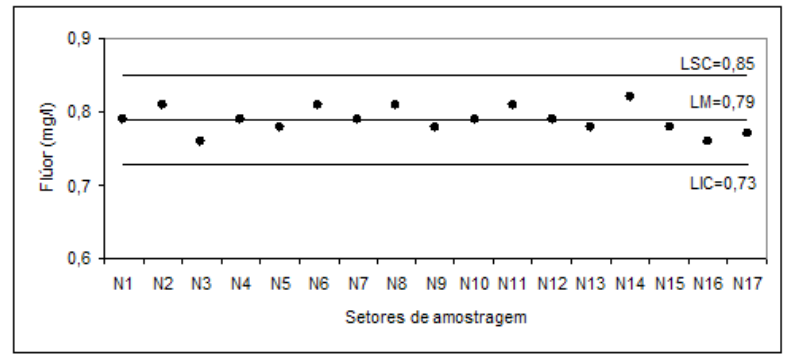

Fonte: Adaptado pelos autores

Conforme a Figura 2, o processo está sob Controle Estatístico de Qualidade, visto que nenhum ponto caiu fora da região de normalidade.

De acordo com a Portaria 518 MS, a concentração ideal de flúor, na rede de abastecimento, não deve passar de $1,5 \mathrm{mg} / 1$.

Ramires et al. (2006), em um estudo publicado na Revista Saúde Pública, em 2006, ao analisarem amostras da água quanto ao teor de flúor, consideraram como "aceitáveis" os níveis entre 0,55 a $0,84 \mathrm{mg} / 1$ e como "inaceitáveis", os níveis que se apresentaram fora deste intervalo.

Vidal et al. (2006), ao avaliarem a concentração de flúor na água de abastecimento do município de Torres/RS por um período de 7 meses, notaram uma oscilação entre 0,29 e $0,91 \mathrm{mg} / \mathrm{l}$, com uma média de $0,62 \mathrm{mg} / 1$.

A Figura 3 apresenta os valores do $\mathrm{pH}$, nos setores de amostragem da rede de distribuição, no período de janeiro a dezembro de 2009 .

Figura 3 - pH nos setores de amostragem da rede de distribuição.

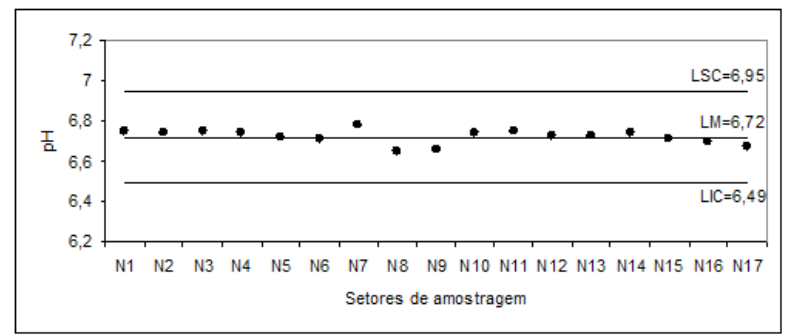

Fonte: Adaptado pelos autores 
Como nenhum ponto caiu fora da região de normalidade, o processo está sob Controle Estatístico de Qualidade. Além disso, está dentro das especificações da Portaria vigente, a qual recomenda que, no sistema de distribuição, o pH da água deve ser mantido na faixa entre 6,0 e 9,5. Os valores da Turbidez, nos setores de amostragem, são mostrados na Figura 4.

Figura 4 - Turbidez nos setores de amostragem da rede de distribuição.

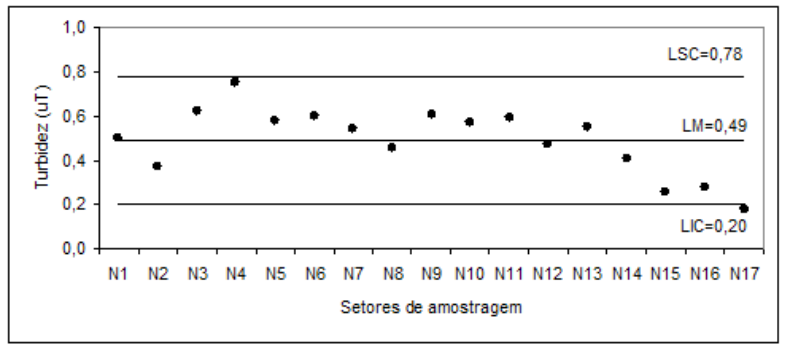

Fonte: Adaptado pelos autores

Nota-se que apenas o setor 17 não está sob Controle Estatístico, porém, não há problemas, visto que o objetivo é obter a turbidez mais baixa possível. Os demais pontos estão na região de normalidade, ou seja, a qualidade da água está adequada aos consumidores, já que a Portaria vigente indica que o limite máximo para qualquer ponto da rede, no sistema de distribuição, deve ser de 5,0 uT. Os valores para a Cor da água, nos setores de amostragem, são mostrados Figura 5.

Figura 5 - Cor nos setores de amostragem da rede de distribuição.

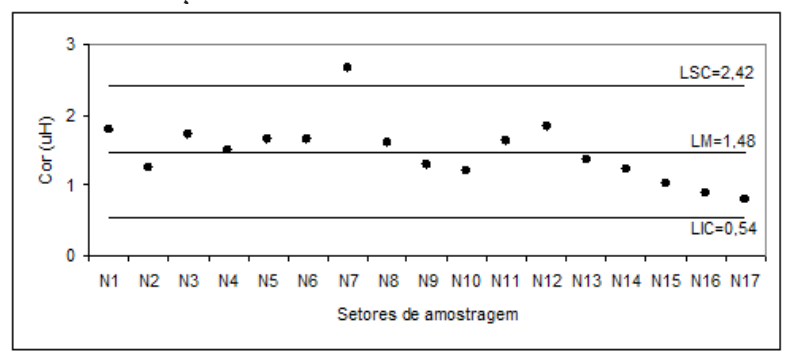

Fonte: Adaptado pelos autores
A Figura 5 mostra que o setor (N7) não está sob Controle Estatístico, já que apresenta valores fora da região de normalidade. Entretanto, o resultado está de acordo com a Portaria 518/04, do Ministério da Saúde, a qual recomenda que, no sistema de distribuição, o valor máximo permissível de cor aparente, na água distribuída, é de $15 \mathrm{uH}$.

Pierin et al. (2005) relatam que a maioria das empresas de saneamento do Brasil, para monitoramento da qualidade da Água, utiliza o Índice de Qualidade da água (IQA), que acompanha 10 parâmetros: Fluoreto, Cloro residual, Cor aparente, pH, Turbidez, Ferro total, Manganês, Matéria orgânica, Coliforme total e Coliforme termotolerante.

Esses autores comentam, ainda, que, quando os parâmetros, Fluoreto, Cloro residual, Cor aparente, pH, Turbidez, Ferro total e Manganês, estiverem com seus valores próximos aos limites estabelecidos pela Portaria 518 MS, necessitam de ações preventivas, e quando estiverem com seus valores fora dos limites estabelecidos pela Portaria 518 MS, necessitam de ações corretivas.

È importante ressaltar que, quando os técnicos responsáveis pelo abastecimento identificarem amostras fora do padrão de potabilidade, nos respectivos setores, devem, imediatamente, verificar as causas e tomar as devidas medidas corretivas, tais como: descarga na rede de distribuição para a eliminação dos problemas de água suja; em alguns casos, reforço na cloração, para a estabilização dos níveis de cloro; e recoleta para a verificação da potabilidade da água.

Cabe ressaltar que, no período de coletas e análises físicas e químicas das amostras, também foram realizadas análises bacteriológicas, porém, nenhuma amostra apresentou qualquer contaminação. 


\section{Conclusões}

Opresente estudo teve como objetivo a proposição de mm plano mensal de coleta de amostras de água, em diversos pontos da rede de distribuição, com o intuito de desenvolver uma estratégia de controle que mantenha a rede de abastecimento de água em constante vigilância e, assim, garanta a potabilidade da água que chega aos consumidores, desde a saída da ETA até as ligações domiciliares.

O estudo concluiu que:

- O programa de monitoramento implantado permitiu a identificação de trechos críticos da rede de distribuição, nos quais, muito provavelmente, por problemas de acúmulos de sujeiras precipitadas e por incrustações nas paredes internas, a qualidade da água tratada mostrou-se comprometida, com destaque para valores da turbidez e da cor. Apesar disso, a água distribuída atende, adequadamente, ao padrão bacteriológico de potabilidade.

- O plano mensal de amostragem, conduzido de acordo com os critérios estabelecidos pela Portaria no 518/2004 do Ministério da Saúde, adotado para a água tratada, tem proporcionado ao SAMAE um completo controle da qualidade da água, em todas as etapas, desde a produção até a distribuição, e ao usuário, a garantia da potabilidade da água fornecida.

\section{Agradecimento}

Os autores agradecem ao Serviço Autônomo Municipal de Água e Esgoto de Ibiporã - Pr. (SAMAE), que permitiu a aplicação desta metodologia, liberando funcionários e as dependências laboratoriais.

\section{Referências}

ABREU, L. M.; GRANEMANN, S. R.; GARTNER, I.; BERNARDES, R. S. Escolha de um programa de controle da qualidade da água para consumo humano: aplicação do método AHP. Revista Brasileira de Engenharia Agrícola e Ambiental, Campina Grande, v. 4, n. 2, p. 257-262, 2000.
AMERICAN PUBLIC HEALTH ASSOCIATION. Standart methods for the examination of water and wastewater. 18. ed. Washington: APHA, 1998.

BRASIL. Ministério da Saúde. Portaria $M S n^{o} 518$, de 25 de março de 2004. Estabelece os procedimentos e responsabilidades relativos ao controle e vigilância da qualidade da água para consumo humano e seu padrão de potabilidade, e dá outras providências. Brasília, 2004.

COSTA, R. H. R.; MEDRI, W.; SANTOS, D. M. Controle estatístico de processo na rede pública de abastecimento de água. In: CONGRESO INTERAMERICANO DE INGENIERÍA SANITARIA Y AMBIENTAL, 28., Cancún. Anais... Cancún: AIDIS, 2002.

LECHEVALLIER, M. W. Coliform regrowth in drinking water: a review. Journal of American Water Works Association, v. 11, n. 82, p. 74-86, 1990.

MEDRI, W. Plano probabilístico de amostragem para o controle da qualidade bacterilógica da água em redes de abastecimento. 1993. Dissertação (Mestrado em Engenharia de Produção), Universidade Federal de Santa Catarina, Florianópolis.

MEDRI, W.; COSTA, R. H. R. Modelo probabilístico de amostragem para controle da qualidade bacteriológica da água em redes de distribuição. Engenharia Sanitária, Ambiental, Rio de Janeiro, v. 6, n. 4, p. 100-107, 2001.

MONTGOMERY, D. C. Introdução ao controle estatístico da qualidade. Tradução de Ana Maria Lima de Farias e Vera Regina Lima de Faria e Flores. 4. ed. Rio de Janeiro: LTC, 2004.

PIERIN, C. E.; KULCHESKI, E.; GIONGO, E. M. S.; CHIARELLO, C. I.; SILVA, D. A. ACQAD- Avaliação de conformidade da qualidade da água distribuída nos 616 sistemas operados pela Sanepar no Estado do Paraná. Sanare: Revista Técnica da Sanepar, Curitiba, v. 23, n. 23, p. 4-16, jan./dez., 2005.

RAMIRES, I.; MAIA, L. P.; RIGOLIZZ, D. S.; LAURIS, J. R. P.; BUZALAF, M. A. R. Heterocontrole da fluoretação da água de abastecimento público em Bauru. Revista de Saúde Pública, São Paulo, v. 40, n. 5, p. 883-889, 2006.

VIDAL, S. G.; TOVO, M.F.; KRAMER, P.F.; RUSCHEL, H. C.; FERREIRA, E. H. Heterocontrole da fluoretação de águas de abastecimento público do município de Torres/ RS. Stomatos: Revista de odontologia da Universidade Luterana do Brasil, Canoas, v. 12, n. 22, p. 5-9, 2006.

Recebido em 30 Maio 2011- Received on May 30, 2011.

Aceito em 2 Outubro, 2011 - Accepted on October 2, 2011. 